\title{
IMPROVEMENT OF STUDENTS CRITICAL THINKING THROUGH THE USING OF THE METHOD OF CASE STUDIES
}

Darya Sergeevna Zaudalova

Kazan Federal University, Kazan, Russia.

Svetlana Vladimirovna Karkina Kazan Federal University, Kazan, Russia.

Singh Balwant

PhD Partap College of Education, India, Ludhiana

E-mail:s.karkina@mail.ru

Recepción: 05/08/2019 Aceptación: 09/09/2019 Publicación: 23/10/2019

\section{Gitación sugerida:}

Zaudalova, D.S., Karkina, S.V. y Balwant, S. (2019). Improvement of students critical thinking through the using of the method of case studies. 3C TIC. Cuadernos de desarrollo aplicados a las TIC. Edición Especial, Octubre 2019, 152-163. doi: https://doi. org/10.17993/3ctic.2019.83-2.152-163

\section{Suggested citation:}

Zaudalova, D.S., Karkina, S.V. \& Balwant, S. (2019). Improvement of students critical thinking through the using of the method of case studies. 3C TIC. Cuadernos de desarrollo aplicados a las TIC. Special Issue, October 2019, 152-163. doi: https://doi. org/10.17993/3ctic.2019.83-2.152-163 


\section{ABSTRACT}

The conditions of modernization of modern reality require the introduction of new teaching methods that consider the subjective needs of the individual and provide for anybody with the opportunity to build an individual trajectory of development. The development of critical thinking among students in the modern education system is one of the important directions in the development of moral, comprehensively developed personality. In addition to the fact that critical thinking is metasubject and can be applied in all spheres of life, it is necessary to optimize the work of students in different subjects of the educational program. The study used method of case study that is one of the very perspective instruments for the improvement of the educational theory and practice. Case study is a method that uses description of situation from real educational practice and life at all. Working with each situation allows you to develop the ability to analyze, draw conclusions, evaluate and interpret. Cases contain not only information about the situation, but also additional sources of information, such as illustrations or criteria for their evaluation. We have developed a technique for the development of critical thinking in the process of creating illustrations for literary works in the technique of linocut. Within the framework of this technique, nine cases have been developed. The study concluded that the advantage of cases is the ability to optimally combine theory and practice. The method of cases contributes to the development of the ability to analyze, interpret, draw conclusions on a specific situation and evaluate, choose the best option and plan its implementation, which can significantly improve the efficiency of critical thinking in students.

\section{KEYWORDS}

Critical thinking, Case studies, High education, Student, Personal development. 


\section{INTRODUCTION}

The conditions of modernization of modern reality require the introduction of new teaching methods that consider the subjective needs of the individual and provide for anybody with the opportunity to build an individual trajectory of development. The free development of the individual is relevant on a global scale and characterizes the main trends in the development of world consciousness. According to literature research "The problem of free will, one of the most serious ones for the Western civilization as a whole" (Smyslova \& Khabibullina, 2016). Some of modern researchers such as Nurgayanova, Ahmetova and Batyrshina (2015) highlight the importance of intercultural interaction in the process of personal development (Kheirabadi \& Mirzaei, 2019; Borisova et al., 2017). The educational possibilities of ethno-confessional environment were studied by Faizrakhmanova and Kovrikova (2017) (Kashisaz \& Mobarak, 2018). The importance in this context is the task of education an "individual capable of artistic and creative re-comprehension and the development of the surrounding world in accordance with the laws of beauty" (Akhmetshina \& Kadyjrova, 2017). Such researchers as Valeeva, Karkina and Starčič (2018) study the ways for activization of individual capable by the using of personal-oriented approach, when other researchers like Butenko and Khodos (2002) state as most important trend the improvement of critical thinking.

The development of critical thinking among students in the modern education system is one of the important directions in the development of moral, comprehensively developed personality. Critical thinking is necessary to optimize the work of students in different subjects of the educational program (Murasheva et al, 2018; Eslami \& Ahmadi, 2019; Jabbari et al., 2019; Ogar et al., 2018).

In Cottrell's work (2017) critical thinking is defined as comparison of arguments and proofs for and against. Also, in her work, she refers to the definition of E. Glazer. He says that "critical thinking implies constant attempts to examine any beliefs or knowledge in the light of the testimonies that support them and the conclusions they reach". 
The author of the definition also emphasizes the importance of three aspects of critical thinking: constancy - careful consideration of the issue and return to it, proof - evaluation of the evidence put forward in favor of the proposal or point of view, consequence - reflection on what may lead to the assumption or point of view, what conclusions can be drawn, whether they are applicable, rational, and if not, whether the original assumptions or points of view should be revised.

Dianov (2014) in his work refers to two definitions. One highlights critical thinking as the ability to analyze information from the standpoint of logic, the ability to make informed judgments, decisions and apply the results to both standard and non-standard situations, issues and problems. The second belongs to Canadian Professor R. Johnson. He states that critical thinking is a special kind of mental activity that allows a person to make a sound judgment about the proposed point of view or model of behavior.

Also Dianov (2014) refers to the works of R. Paul, one of the leading experts of the United States in the field of theory and practice of critical thinking, who says that "critical thinking is thinking about thinking, that is, when a person thinks in order to improve thinking".

\section{METHODS}

The study used method of case study that is one of the very perspective instruments for the improvement of the educational theory and practice. Case study is a method that uses description of situation from real educational practice and life at all. According to the instruction students should research the situation, the meaning of the problem, offer possible ways for decision and chose the best from them (Vinevskaya, 2015; Nakhaee \& Nasrabadi, 2019). Cases are based on the real facts or very close to the real life conditions. Currently, in connection with the modernization of Russian education in the systems of secondary and higher education in Russia is the introduction of the case-method as one of the new and effective methods of training. 


\section{RESULTS AND DISCUSSION}

Critical thinking, like informal logic, views knowledge as a property of the whole community, not just of the individual. Questions and criticism determine the strategy of reasoning analysis. With their help, there is an improvement and expansion of the original knowledge, and not the creation of self-evident knowledge on a clear, reliable Foundation. Critical thinking focuses on the analysis of "natural" reasoning, not trying to fit them under the standard structure of formal logic. Procedures of reasoning, as already noted, are analyzed in the "anthropological" context, considering the characteristics of the reasoning subject, which is characterized by a certain will, objectives, educational and professional level.

Critical thinking is focused on "participation" in the social and individual life of a person: reasoning is applied not only in the scientific sphere, but also in other areas of human activity, including the sphere of his everyday life. Within the framework of critical thinking, we study "how a person thinks", making decisions, planning his / her life activity and implementing his / her practical plans. One of the tasks of critical thinking is to influence the level of "practical rationality" of society, including those who make decisions and those who implement them.

Currently, the case-method is actively implemented in the practice of the educational process in Russia. The case study introduces students to a specific real situation, designed to analyze different types of information, its generalization, problem formulation skills and the development of possible solutions in accordance with the established criteria. A distinctive feature of the case-method is the independent activity of students, during which there is the assimilation of knowledge and the formation of skills, as a result of which there is a creative mastery of professional skills and the development of mental abilities.

Educational cases can be based on several types of research:

1. An explanatory study in which an explanation of a case or phenomenon occurs. 
2. The pilot case study is a preliminary study. Its purpose is to prove the need for further study of the problem.

3. Collective research - the study of information about several ready-made studies, the use of the results and experience of past work.

4. The instrumental study refers to a specific case to get an idea of the phenomenon.

5. Descriptive study - a study which introduces the problem, "enters in" (Gaur et al., 2019).

Among the variety of techniques of fine arts we have chosen linocut. This is a technique of printing graphics, is an engraving on linoleum or similar polymerplastic materials. It belongs to the group of high-print engravings.

According to certain features of its performance, linocut is characterized by limited opportunities for students by transferring the image only with black paint and paper color. In the absence of students' experience in this technique of printed graphics, the transfer of realistic images in this technique is impossible, which allows students to focus on both graphic means of expression (stroke, spot), and to enhance their ability to stylize the image, through critical analysis.

We have developed a technique for the development of critical thinking in the process of creating illustrations for literary works in the technique of linocut. Within the framework of this technique, nine cases have been developed. Working with each situation allows you to develop the ability to analyze, draw conclusions, evaluate and interpret. Cases contain not only information about the situation, but also additional sources of information, such as illustrations or criteria for their evaluation. Work with each case can be both group and individual. 
The cases developed by us consist of 4 blocks and include:

- Situation (Block 1) - this block contains the problem situation with which students will work. The situation is brief, describes a specific example. The theme of the situation is artistic creativity, illustration. The described situation does not have a title or a brief description, with the main idea of the text highlighted. The text of this block also provides links to annexes (block 4), which can be accessed by students in order to better understand the situation.

- Questions (Block 2) - this block includes several questions, the answers to which help to understand the problems of the situation from block 1. Search for answers to questions allows you to better identify the topic of the problem situation, better navigate in its structure. Each of the questions is subject to a single goal of development of critical thinking and allows you to develop the ability to analyze, the ability to interpret, the ability to make a conclusion and the ability to assess. When working with this block, students can also access applications from block 4 if the task requires it.

- Practical task (Block 3) - within this block, students perform a creative practical task presented in each of the cases with its own conditions and rules. The purpose of this block is to summarize the data obtained in the course of working with the problem situation and consolidate the skills of analysis, interpretation, conclusion and evaluation in practice. If this is required by the practice assignment, students can also access the applications in block 4 .

- Applications (Block 4) - this block includes data that helps to solve issues and problem situations while working with other blocks from the case (blocks $1,2,3)$. The appeal to the applications is a variable part, but it will significantly increase the probability of the correct execution of tasks from the case and will allow you to better develop the skills of critical thinking. The information provided in the appendices are reproductions of works by artists and memos to consolidate oral knowledge in the field of illustration and artistic creativity. 
Topics of developed cases:

- Illustration as an art form

- Composition as an illustration

- How to work with composition

- Graphic as a mean of expression

- What is stylization
- Stylization by means of graphic expressive means

- Introduction to linocut

- Sketch for linocut

- The illustration in the technique of linocut

\section{SUMMARY}

The application of the case-method is a complex and structured process in which a significant role is played by the levels of preparedness of the teacher and students to the activities within the case-method.

The case-method promotes the development of critical thinking and motivates students to study a specific topic in detail. This method also helps students stimulate conversation between student and teacher. This is the most active method of learning, allowing the best way to reveal the talent of students. Many teachers use the case-method to improve the ability to learn. This teaching method is an alternative to the class-lesson system of education in the classroom. The casemethod is a powerful tool that connects the learning environment and the real world.

\section{CONCLUSIONS}

The development of critical thinking is an important part of the process of personal development of students in the classroom of fine arts. The process of creating an art object requires not only the possession of techniques of performing art works, but also a special way of thinking that allows you to analyze works of art, to justify and formulate conclusions about the harmonious composition of the image. The chosen case-method is best suited for the development of critical thinking. 
Features of its structure allow to work out the basic mechanisms of critical thinking - analysis, formulation of conclusions, evaluation and interpretation of the results. Mastering the technique of linocut requires the conditions for the development of students' critical analysis skills necessary in the process of image stylization. Features of performance in this technique limit the artistic methods of image transmission, which contributes to the activation of critical analysis processes in students.

The case-method can be used in different areas of educational activity and for different ages, so it is a promising pedagogical technique for further study.

\section{ACKNOWLEDGEMENTS}

The work is performed according to the Russian Government Program of Competitive Growth of Kazan Federal University.

\section{REFERENCES}

Akhmetshina, E. G., \& Kadyjrova, L. H. (2017). Pedagogical approaches to the development system of artistic culture of individual. Revista san gregorio, (20), 188-193. Retrieved from https://dialnet.unirioja.es/servlet/ articulo? codigo $=6236963$

Borisova, O. V., Vasbieva, D. G., Malykh, N. I., Vasnev, S. A., \& Vasneva, N. N. (2017). Trends and Challenges in Development of Continuing Vocational Education and Training in Russia. International Electronic Journal of Mathematics Education, 12(1), 69-78. Retrieved from https://www.iejme.com/ article/trends-and-challenges-in-development-of-continuing-vocationaleducation-and-training-in-russia

Butenko, A. V., \& Khodos, E. A. (2002). Critical thinking: Method, theory, practice. 
Cottrell, S. (2017). Critical thinking skills: Effective analysis, argument and reflection. Macmillan International Higher Education.

Dianov, A. (2014). Mozg: populyarnaya entziklopedia. Eksmo, 224 p.

Eslami, R., \& Ahmadi, S. (2019). Investigating the Role of Educational Media on Secondary School Students' Learning Process Improvement in Jahrom City. Fournal of Humanities Insights, 3(01), 13-16. doi: https:// doi.org/10.22034/ jhi.2019.80890

Faizrakhmanova, L. T., \& Kovrikova, E. V. (2017). The Ethno-Confessional Relations in the Context of Culture and Education (Kazan province, XVIII-beginning of XX century). Bylye Gody, 43(1), 30-39. doi: https://doi. org/10.13187/bg.2017.1.30

Gaur, D., Bhatia,J., \& Priya, A. (2019). Case Study: A Contemporary Teaching Technique`s Permeation into Real Life. Professionalism in Education. CoConstructiong Professional Knowledge: Learning Across Disciplines. Second Edition 2019. Global Printing Services, New Delhi, 222 - 226.

Jabbari, E., Charbaghi, Z., \& Dana A. (2019). Investigating the Effects of Educational and Motivational Education at Different Levels on the Performance and Application of dart throwing. Fournal of Humanities Insights, 3(02), 37-44. doi: https://doi.org/10.22034/jhi.2019.80896

Kashisaz, S., \& Mobaraki, E. (2018). The Effects of Private Education Institutes in Providing Modern Financial Knowledge in Developing Countries. Journal of Humanities Insights, 02(04), 172-178.

Kheirabadi, M. A., \& Mirzaei, Z. (2019). Descriptive valuation pattern in education and training system: a mixed study. Fournal of Humanities Insights, 3(01), 7-12. doi: https://doi.org/10.22034/jhi.2019.80889 
Murasheva, A. A., Stolyarov, V. M., Lomakin, G. V., Lepekhin, P. A., \& Tarbaev, V. A. (2018). Evaluate the use of farmlands encumbered with electric grid facilities: damage factors and solution approaches. Opción, 34(852), 677-705.

Nakhaee, J., \& Nasrabadi, M. A. (2019). Strategies for Research-Centered Education of Architectural Designing by Examining the Research-Centered Activities of the Top Universities. Fournal of Humanities Insights, 3(02), 50-56. doi: https://doi.org/10.22034/jhi.2019.80898

Nurgayanova, N., Ahmetova, L., \& Batyrshina, G. (2015). Intercultural interaction of the Volga Region nations in the context of ethnomusical traditions. Biosciences Biotechnology Research Asia, 12(3). doi: http://dx.doi. org/10.13005/bbra/ 1963

Ogar, J. N., Ogar, T. E., \& Bassey, S. A. (2018). Ambivalence Human Nature and Social Justice. UCT Journal of Social Sciences and Humanities Research, 6(2), 20-25.

Smyslova, E. V., \& Khabibullina, L. F. (2016). The problem of Free Will in "The Clockwork Testament or: Enderby's End" by A. Burgess. The Turkish Online Journal of Design, Art and Communication. - Turkey, TOFDAC.

Valeeva, R. A., Karkina, S. V., \& Starčič, A. I. (2018, October). Distance Learning for Aesthetic Education-Informed Professional Development and Life-Long Learning of Student Teachers. In Proceedings of the Sixth International Conference on Technological Ecosystems for Enhancing Multiculturality (pp. 597-603). ACM. doi: https://doi.org/10.1145/3284179.3284283

Vinevskaya, A. V. (2015). Case method in pedagogic: practicum for teachers and students. Rostov na Donu: Pheniks, 141 p. 